\title{
Does intravascular coagulation contribute to the operative mortality for large acoustic neuromas?
}

\author{
CHRISTOPHER MATTOCK, ALAN CROCKARD
}

From the National Hospital for Nervous Diseases, London, UK

SUMMARY Three cases of abnormal bleeding during suboccipital excision of large acoustic neuroma are reported. The possible role of limited operative intravascular coagulation is discussed.

The safety of acoustic neuroma excision has improved throughout this century. ${ }^{1}$ Notable advances include Harvey Cushing's introduction of the bilateral suboccipital approach, ${ }^{2}$ Atkinson's recognition of the importance of the anterior inferior cerebellar artery, ${ }^{3}$ recognition of the importance of early diagnosis, ${ }^{4}$ and finally the introduction of the operating microscope and microsurgical technique. Eighty years ago mortality was as high as $80 \%$, but may now be lower than $4 \% .^{5}$ The lowest figures relate to tumours of less than $2.5 \mathrm{~cm}$ diameter. Mortality with tumours over $4 \mathrm{~cm}$ however, may still approach $20 \%$, and many authors have commented upon the relationship between operative mortality and tumour diameter. ${ }^{67}$ The risk factors with large tumours are undoubtedly multiple. Brainstem compression, longer anaesthetic times, damage to the anterior inferior cerebellar artery, and brainstem trauma during retraction have all been discussed.

We suggest there is a further but remediable cause in some cases. This is a coagulation defect resulting from previously unrecognised intraoperative thromboplastin release. Intravascular coagulation is associated with infection, tumours, injury and with brain tissue destruction following head trauma. ${ }^{89}$ Excision of a large acoustic neuroma with tumour destruction might similarly release thromboplastin and cause a transient coagulopathy. We report three patients in whom this operative complication was strongly suspected.

Address for reprint requests: Mr A Crockard, the National Hospital for Nervous Diseases, Queen Sq, London WCIN 3BG, UK.

Received 28 June 1985 and in revised form 24 October 1985. Accepted 2 November 1985

\section{Surgical technique}

In a cinsecutive series of 67 cases of acoustic neuroma removed in the last five years by the same surgeon (AC) the age range has been 19 to 74 years with 35 males and 22 females. The tumour was greater than $4 \mathrm{~cm}$ in diameter in 33 cases, and in all of these larger tumours a similar surgical technique has been used. Each patient was anaesthetised, ventilated and placed in the "park bench" position. Access to the tumour was obtained via a suboccipital muscle splitting incision and occipital craniectomy. A subpial excision of the lateral quarter of the cerebellum allowed good exposure with minimal brainstem retraction. A microscopic removal of the intracapsular contents with rongeurs and CUSA (Cavitron Ultrasonic Surgical Aspirator) preceded excision of the capsule. Anatomical preservation of the facial nerve was attempted in all cases and was successful in 19 cases, although functional recovery has been noted in only eight of these patients with large tumours. Including the two reported below, there have been four deaths in the series. (Two bleeding, one myocardial infarction and one septicaemia.) Histology was confirmed as schwannoma in all cases, and no patient had a previous history of abnormal bleeding.

\section{Case records}

Case 1 A 55-year-old woman presented with a right-sided $4.5 \mathrm{~cm}$ acoustic neuroma. Prior to excision a ventriculoperitoneal shunt was inserted. Operation was performed as above, and the patient was normotensive throughout and received two units of blood. She wakened easily from anaesthetic with only a facial weakness, but two hours later became drowsy and lapsed into coma. An emergency CT scan revealed a large posterior fossa haematoma. At reexploration this clot was evacuated but generalised oozing could not be controlled and, despite all surgical and haematological manipulations, she died the following day. Postoperative results suggested intravascular coagulation with a reduction in platelets to $91 \times 10^{9} / 1$, and shortened thrombin time and partial thromboplastin times consistent with activation of coagulation pathways but not exhaustion of clotting factors. Fibrin degradation products were raised at $80 \mu \mathrm{g} / \mathrm{ml}$ (normal less than $10 \mu \mathrm{g} / \mathrm{ml}$ ). Postmortem exam- 
ination revealed flame-shaped acute haemorrhages in the brainstem, and acute petechial haemorrhages in the deep cerebellar nuclei.

Case 2 A 64-year-old woman presented with a left-sided $5 \mathrm{~cm}$ acoustic neuroma. At operation the tumour was soft and not particularly vascular. After 3 hours operating there was a generalised capillary ooze from the skin, subcutaneous tissue, divided muscle and the tumour bed. These sites had previously been "dry". There was no change in systemic blood pressure. The bleeding improved with an infusion of two units of fresh frozen plasma and local application of hydrogen peroxide. Haemostasis was not complete despite all measures and the patient was hyperventilated for 24 hours with controlled hypotension. A postoperative CT scan showed widespread blood in the posterior fossa. Respiratory complications ensued and she died ten days later. At postmortem examination widespread blood was present in the posterior fossa with intracerebellar haemorrhages. All major posterior fossa vessels were patent.

Case 3 A 47-year-old man presented with a right-sided $5 \mathrm{~cm}$ acoustic neuroma. At operation the tumour extended from tentorium to foramen magnum. Total excision with facial nerve preservation was uneventful until the final stages of a layered closure, when a generalised ooze was noted from the skin and subcutaneous tissues. Surgery was completed and the patient awoke without delay. However, two hours later his level of consciousness declined and a re-exploration revealed a large wound haematoma. During this second procedure there was generalised oozing from all sites including skin and muscle despite infusion of four units of fresh frozen plasma. Eventually haemostasis was achieved and the patient recovered to be discharged eight weeks later with minimal unsteadiness and full facial nerve function.

\section{Discussion}

In one series of 120 cases $^{5}$ there were four deaths. Of these three were due to bleeding. Two of these patients had tumours larger than $5 \mathrm{~cm}$ and the other a tumour $3-5 \mathrm{~cm}$ in diameter. As in other series roughly two thirds of the deaths are related to bleeding problems. ${ }^{6}$ If these could be controlled then overall operative mortality should fall. We suspect that unrecognised release of tissue thromboplastin causing limited intravascular coagulation contributes to some of these deaths. The situation may be analogous to that described by Goodnight ${ }^{8}$ where brain tissue necrosis led to a transient and limited defibrination. In their longitudinal studies in untreated patients the condition was self-limiting with return of normal coagulation within 5 to 18 hours of injury, but with a potentially lethal period of a few hours when intracranial haemorrhage might occur spontaneously.

The patients we have presented all had large neuromas. All had clinically normal haemostasis at the beginning of their craniectomy which became abnormal later. In Case 1 abnormal bleeding in association with thrombocytopenia, activated coagulation and a small rise in fibrin degradation products is consistent with limited intravascular coagulation. In both Cases 2 and 3 there was excessive bleeding which was improved by infusion of fresh frozen plasma, and therefore there was speculation as to whether limited defibrination had occurred. In neither case were appropriate samples taken prior to infusion of coagulation factors. However, estimates of prothrombin, partial thromboplastin, and thrombin times were unremarkable following infusion, as were fibrin degradation products.

If transient limited defibrination does occur during acoustic surgery, what is the source of the thromboplastin? In our cases there are three possible sources, the fragments of tumour, the resected cerebellum and least likely, infarction of the lateral pons. We believe the likely source of thromboplastin is the tumour itself whilst it is removed by CUSA or rongeurs. CUSA would seem to be a potent method for releasing tissue thromboplastin as it produces a near homogenate, and the larger tumours might release more thromboplastin. We assume that we have not seen bleeding with smaller acoustic neuromas as they are generally removed whole or in few pieces. The cerebellar resection is an unlikely major source, as at least two series have reported no increased mortality associated with preliminary partial cerebellar resection. ${ }^{110}$

It can be argued that our patients suffered trauma to the anterior inferior cerebellar artery resulting in pontine infarction and thromboplastin release. However in no patient were there the autonomic changes emphasised by Atkinson, ${ }^{3}$ namely a sudden rise in blood pressure and pulse rate, and an abnormal pattern of respiration marking the clipping of the artery. Neither was there the postoperative high fever he described. At necropsy in all cases the anterior inferior cerebellar artery was patent and the distribution of haemorrhage and infarction was inconsistent with occlusion of that vessel.

A two-stage procedure has been reported in 23 patients with very large neuromas, with no deaths and no reported bleeding. ${ }^{11}$ It is interesting to speculate as to whether part of this success may relate to two-stage release of tumour thromboplastin.

Whatever the source of thromboplastin the treatment is identical. Immediate replacement of fibrinogen, factor V, and factor VIII may be required, as recommended by Goodnight, ${ }^{8}$ and we agree that heparin and epsilon-aminocaproic acid are inappropriate. Platelet concentrates, not readily available in 1974 should also be considered if the platelet count falls below $100 \times 10^{9} / 1$.

A prospective study of coagulation during surgery for large acoustic neuroma is now indicated. This should include serial studies of fibrinogen, fibrin degradation products, and factor $\mathrm{V}$ during, and in the first few hours following surgery. 
We conclude that limited and transient intravascular coagulation may complicate excision of large acoustic neuromas, and may contribute to some of the operative deaths from intracranial bleeding, and that the possibility of a coagulopathy during surgery for large acoustic neuromas should be recognised and fresh frozen plasma must be available, and the infusion of platelet concentrates be considered should abnormal bleeding occur.

\section{References}

${ }^{1}$ Thomsen J. Suboccipital removal of acoustic neuromas: results of 125 operations. Acta Otolaryngol 1976; 81:406-14.

${ }^{2}$ Cushing H. Tumors of the Nervus Acusticus and Syndrome of the Cerebellopontine Angle. Philadelphia: WB Saunders, 1917.

${ }^{3}$ Atkinson WJ. The anterior inferior cerebellar artery. $J$ Neurol Neurosurg Psychiatry 1949;12:137-51.

${ }^{4}$ House WF. Monograph I: Transtemporal microsurgical removal of acoustic neuroma. Arch Otolaryngol 1964;80:596-756.

${ }^{5}$ Yasargil MG, Fox JL. The microsurgical approach to acoustic neurinomas. Surg Neurol 1979;2:393-98.

${ }^{6}$ King TT, Morrison AW. Translabyrinthine and transtentorial removal of acoustic nerve tumours. Results in 150 cases. $J$ Neurosurg 1980;52:210-6.

7 Olivecrona H. Acoustic Tumours. J Neurosurg 1967; 16:6-13.

${ }^{8}$ Goodnight SH, Kenoyer G, Rappaport SI, Patch MJ, Lee JA, Kurze T. Defibrination after brain tissue destruction-a serious complication of head injury. N Engl J Med 1974;290:1043-7.

${ }^{9}$ Kaufman HH, Hui KS, Mattson JC, et al. Clinicopathological correlations of disseminated intravascular coagulation in patients with head injury. Neurosurgery 1984;15:34-42.

${ }^{10}$ Hullay J, Tomits GH, Gombi R, Velok G. Experiences in radically operated acoustic tumours. Acta Neurochir (Wein) 1975;32:69-72.

${ }^{11}$ Sheptak PE, Jannetta PJ. The two-stage excision of huge acoustic neuromas. J Neurosurg 1979;51:37-41. 